This is an author produced version of a paper published in Oecologia. This paper has been peer-reviewed and is proof-corrected, but does not include the journal pagination.

Citation for the published paper:

Ranius, T. (2001) Constancy and asynchrony of Osmoderma eremita populations in tree hollows. Oecologia.

Volume: 126 Number: 2, pp 208-215.

http://dx.doi.org/10.1007/s004420000515

Access to the published version may require journal subscription.

Published with permission from: Springer Verlag

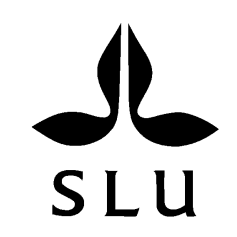

Epsilon Open Archive http://epsilon.slu.se 
Should be cited as:

Ranius, T. (2001) Constancy and asynchrony of Osmoderma eremita populations in tree hollows. Oecologia 126:208-215

DOI $10.1007 / \mathrm{s} 004420000515$

Available at:

http://www.springerlink.com/content/0029-8549

\title{
Constancy and asynchrony of Osmoderma eremita populations in tree hollows
}

\section{Thomas Ranius}

T. Ranius, Department of Zoology, University of Lund, Helgonav. 3, 22362 Lund, Sweden email: thomas.ranius@zool.lu.se Tel.: +46-46-2229334, Fax: +46-46-2224541

\begin{abstract}
A species rich beetle fauna is associated with old, hollow trees. Many of these species are regarded as endangered, but there is little understanding of the population structure and extinction risks of these species. In this study I show that one of the most endangered beetles, Osmoderma eremita, has a population structure which conforms to that of a metapopulation, with each tree possibly sustaining a local population. This was revealed by performing a mark-release-recapture experiment in 26 trees over a 5-year period. The spatial variability between trees was much greater than temporal variability between years. The population size was on average 11 adults tree- 1 year -1 , but differed widely between trees ( $0-85$ adults tree ${ }^{-1}$ year $\left.^{-1}\right)$. The population size in each tree varied moderately between years [mean coefficient of variation $(\mathrm{C} . \mathrm{V})=0.51$.$] , but more widely than from sampling errors alone (P=0.008$, Monte Carlo simulation). The population size variability in all trees combined, however, was not larger than expected from sampling errors alone in a constant population (C.V. $=0.15$, $P=0.335$, Monte Carlo simulation). Thus, the fluctuations of local populations cancel each other out when they are added together. This pattern can arise only when the fluctuations occur asynchronously between trees. The asynchrony of the fluctuations justifies the assumption usually made in metapopulation modelling, that local populations within a metapopulation fluctuate independently of one another. The asynchrony might greatly increase persistence time at the metapopulation level (per stand), compared to the local population level (per tree). The total population size of $O$. eremita in the study area was estimated to be 3,900 individuals. Other localities sustaining $O$. eremita are smaller in area, and most of these must be enlarged to allow long-term metapopulation persistence and to satisfy genetic considerations of the $O$. eremita populations.
\end{abstract}

Keywords: Local population, Mark-release-recapture, Metapopulation, Population size, Population variability 


\section{Introduction}

In the last decade, metapopulation models have been commonly considered in conservation work (e.g. Hanski and Simberloff 1997), even when it is not known whether metapopulation dynamics are of importance (Doak and Mills 1994). One important assumption usually made in metapopulation models is that local populations within a metapopulation fluctuate asynchronously (e.g. Foley 1997; Hanski et al. 1995). If the dynamics of populations are asynchronous, it is unlikely that all populations will suffer extinctions at once. However, widespread synchrony in a metapopulation implies that an unfavourable year would affect all local populations in a similar way. Therefore, a temporal environmental correlation between local populations could severely increase the risk of extinction risks for the metapopulation (e.g. Harrison and Quinn 1989; Thomas and Hanski 1997). Studies on populations of aphids, moths and butterflies suggest that fluctuations often occur more or less in synchrony over areas of 200,000 km² or more (Hanski and Woiwod 1993; Pollard and Yates 1993; Sutcliffe et al. 1996). If strong synchrony between populations were a common pattern, it may threaten to undermine the theoretical importance of metapopulation dynamics in predicting the long-term survival of populations. Several studies on a smaller spatial scale have, however, revealed fluctuations which were not synchronous (Kindvall 1996; Thomas 1991). Therefore, there is a need for empirical studies to assess the degree of synchrony between local populations, especially of rare species as they are of most interest to conservationists.

Metapopulation persistence increases with the number of interacting local populations forming the metapopulation (Hanski et al. 1996). Their persistence is also dependent on characteristics of the populations which influence the rate of local colonization (such as the dispersal ability) and extinction (such as the local population size and its variability). A small population size increases the risk of local extinction due to demographical accidents (e.g. Goodman 1987; Pimm 1991) and loss of genetic variation (Frankham 1995a; Saccheri et al. 1998). Variation through time would also increase demographic risks, because among populations with equal mean population size, populations with larger fluctuations become small more often (e.g. Wright and Hubbell 1983; Pimm 1991).

This is a study of the populations of a beetle, Osmoderma eremita Scopoli (Coleoptera: Scarabaeidae), living in tree hollows. O. eremita and many other species associated with hollow trees have relict distributions with small, isolated populations in pasture woodlands and old-growth forests (O. eremita: Luce 1996; other species: McLean and Speight 1993; Speight 1989). The habitat occupancy (Ranius 2000) and the dispersal rate of marked adults (Ranius and Hedin, in press) suggest that the O. eremita populations conform to a 
metapopulation structure, with each tree possibly sustaining a local population and with the local populations in a stand of trees interconnected to a metapopulation. O. eremita is listed in Annex IV of the European Union Habitats Directive, which sanctions strict protection of the species (Anonymous 1992). However, at present it is impossible to determine the requirements for the long-term persistence of $O$. eremita and other species living in hollow trees, as basic data on their population ecology are lacking.

In a living hollow tree, partly decomposed wood inside the trunk is surrounded by sound, growing wood, resulting in a continuous nutrient supply for the saproxylic fauna. The daily microclimate fluctuations are much smaller in a trunk hollow than at the surface of the trunk (Park and Auerbach 1954; Kelner-Pillault 1974). Owen and Gilbert (1989) have proposed that saproxylic insects associated with tree hollows have constant population sizes as the nutrient supply and microclimate are stable, but in their study on hoverflies, the sample size of species living in rot holes was too small to achieve any empirical evidence.

This study reports the population size of $O$. eremita in 26 hollow oaks and its temporal variability over a 5-year period. The aim of the study was to examine population size and its variability, both in single trees and overall, and to assess the synchrony of fluctuations of populations in different trees.

\section{Materials and methods}

The species

O. eremita lives in tree hollows, in Sweden mainly in oaks, Quercus robur L., with certain characteristics that affect the microclimate (Ranius and Nilsson 1997). The species inhabits trunk hollows containing large amounts of wood mould, which is loose, rotten wood often mixed with fungi, fragments of dead insects, and the remains of bird nests. The larvae usually construct a cocoon in the autumn after 2 years of development and metamorphosis takes place in the spring of the following year. Thus, development normally takes 3 years, but this may depend on habitat quality (Tauzin 1994). The adults emerge in July-September and never hibernate. In contrast to many other saproxylic beetles they do not visit flowers or sap flows, but remain mainly in the tree hollows (Martin 1993; own observations).

The field work

This study was performed in one of the few remaining landscapes in Northern Europe with a high density of old oaks, which is situated in the province of Östergötland, southeastern Sweden (Antonsson and Wadstein 1991). In this landscape, a $1.5 \times 2-\mathrm{km}$ core area with the 
highest density of very large trees (Bjärka-Säby; $5816^{\prime} \mathrm{N}, 15^{\circ} 46^{\prime} \mathrm{E}$ ) was chosen as the study area. Here, most hollow oaks are scattered throughout pasture woodlands.

In the study area, oaks with trunk hollows probably containing large amounts of wood mould were searched for, and 112 such trees were found. Adults of $O$. eremita were captured using pitfall traps in 26 of these trees. It was not possible to set traps in the other trees since the characteristics of the tree hollows made it impossible, or the trees were on land without public access. To be able to set a trap in a hollow, the entrance hole must be wide enough, $<5$ $\mathrm{m}$ from the ground, and the wood-mould surface not too far from the entrance hole. The traps were empty jars placed with the openings at level with the wood-mould surface. If possible, traps with a top diameter of $7 \mathrm{~cm}$ were used, but in narrow hollows the traps were 5-6 cm wide. There was more than one entrance in ten of the 26 studied trees, but in most trees trapping was impossible in the smaller hollows. Therefore, usually one trap was used per tree, except for two trees in which two traps were set in different hollows. The traps were emptied once a day, and then $O$. eremita was also searched for in the hollows and on trunks. Each beetle was given an individual number by marking the elytra with an insect needle in a drill. Except for the first year of study, sex was determined according to Hansen (1925). After marking, the beetles were released on the surface of the wood mould, and usually the beetles immediately began to dig down into the wood mould. When the traps were emptied, $2.7 \%$ of the beetles were dead. The only discernible injury caused by the handling was that the needle, in some cases, pierced the abdomen, causing haemolymph to leak out. Nilsson (1997) has carried out a study on a smaller beetle species which shows that this kind of injury has little or no effect on survival.

The study was performed over 5 years (Table 1). During two of the years, the trapping started before the first adults had emerged, while during the other 3 years adults were present on the first day of trapping. The trapping ended when the daily total capture fell below one individual, except in 1998, when the trapping ended when two captures per day were performed.

\section{Statistical treatment}

Most individuals (85\%, confidence limits $72-94 \%$ ) tended to remain in the same tree throughout their entire life (Ranius and Hedin, in press), and therefore the individuals in each tree could be viewed as a separate subpopulation. As the traps were set at different positions, depending on how the tree hollows were formed, and there could be either one or two traps in a tree, there might be differences in "catchability" between trees. Differences in catchability 
larger than expected from sampling errors alone were detected even between years in several trees, using a Monte Carlo simulation (unpublished data). Therefore, the population size was, as far as possible, estimated for each tree and year separately.

In a closed population consisting of individuals with equal catchability, the distribution of captures between individuals should conform to a Poisson distribution. This is the basis of Craig's (1953) model, which was used for population estimations in this study. Craig's (1953) model is as follows: $\log n-\log (n-r)=s / n$, in which $n$ is the population size, $r$ is the number of captured individuals and $s$ is the number of captures. If $r$ and $s$ are known, $n$ can be solved by Newton-Raphson's method. The population size estimations were carried out for each tree and year separately in the eight trees with the largest number of captured individuals. For the remaining 18 trees with smaller samples, all capture data were combined and Craig's model was used to yield an estimate of the total population size in these trees. In the estimations, the sexes were combined because there was insufficient data to treat females separately for every tree. This gave rise to an underestimate, as there were differences in catchability between sexes (see Results).

The population sizes were also estimated for three pooled samples including data collected over 4 years (1996-1999, but not 1995, as not all individuals were sexed in that year) from all trees which contained only: (1) males, (2) females and (3) both sexes. The purpose of this was to estimate the sex ratio and the magnitude of the bias which arises in the estimate when both sexes are present.

In addition, the total number of males in 1996 to 1999, inclusive, for all trees combined was estimated using the Jolly-Seber method (Jolly 1965; see also Southwood 1978), in order to yield a population estimate from another, independent method and compare this with the results from Craig's model. The Jolly-Seber method pre-supposes the catchability to be equal for all individuals at a certain moment, but it is allowed to vary in time. In contrast, Craig's model, as it was used in this study, allows the catchability to differ between trees. The JollySebers' method demands more data than Craig's model, so the latter model alone could be used at the per tree level and for females. When using the Jolly- Seber method, the capture data was combined for intervals of 3 days to provide enough captures per occasion.

The population size was considered to be zero in trees where no adults were found in a year. This was because it is reasonable to assume that the population is larger when a few individuals are captured, as opposed to when no individuals are found at all, as the difference in catchability between trees and years does not seem to be so large that it could explain the absence of captures in trees in most cases. 
The temporal variability was characterized by the coefficient of variation (C.V.), which is the ratio between the SD and mean population size. This is the only measure which can be used when there are zeros in the data series (McArdle 1992). The C.V.s were calculated as follows: C.V.=(S.D. of population size per year over 5 years $) /($ mean population size per year). This was estimated both for the populations of individual trees, and for the sum of populations in all trees and the eight trees with the largest populations.

For the eight trees, an arithmetic mean of the C.V.s of individual trees, weighted according to population size per tree, was calculated as follows: mean C.V. for eight trees $=[$ sum of the eight (S.D. of population size per year in a tree over 5 years) $] /($ mean population size per year of the eight trees summed). Computer simulations For each population estimate, a set of computer simulations was conducted to obtain the magnitude of errors due to random sampling. Each simulation was run as follows:

1. The number of individuals was equalled with the actual population size estimated from field data with Craig's model.

2. Captures were randomly distributed between the individuals, until the number of recaptures reached the number of recaptures in the field data.

3. From the figures on the number of captures and number of individuals captured generated from the randomized process above, the population size was estimated by Craig's model.

The simulation was repeated 1,000 times, in order to determine the $95 \%$ confidence limits.

The C.V.s achieved from the field data reflect not only the actual population fluctuations, but also variations of the estimates caused by sampling errors. The C.V.s from the field data were compared with the magnitude of the C.V.s expected from sampling errors alone by using a Monte Carlo simulation. Each simulation run generated the C.V.s over 5 years for eight trees with population sizes constant over time, but with variability in population estimates due to randomized capturing. Each simulation was run as follows:

1. The number of individuals in each tree was equalled with the mean of the population size estimated from field data over 5 years in that tree, and was kept constant over the 5 years.

2. For each of the 40 sets of individuals ( 5 years $\times 8$ trees), captures were randomly distributed between the individuals, until the quotient between recaptures and number of individuals reached the same value as from the field data (recaptures/estimated population size) from the particular tree and year. 
3. The number of captures and number of individuals captured, generated from the randomized process above, were counted for each of the 40 sets of individuals, and the population size was estimated by Craig's model.

4. From the population estimates, C.V.s (for individual trees, and for the eight trees combined) were calculated with the same method as used for the field data.

The simulations were repeated 1000 times, in order to compare the simulated C.V.s with values from field data.

\section{Results}

Population size

In 5 years, 1,541 captures of 723 individuals of $O$. eremita were performed (capture data per year: see Table 1). Of these captures, $89.0 \%$ were performed by pitfall trapping, $8.7 \%$ without use of traps within tree hollows, $1.7 \%$ on trunks of hollow oaks, and $0.6 \%$ on the ground below hollow oaks. Of 818 recaptures, 812 were carried out in the same tree as the previous capture, whereas six took place in a different tree.

The distribution of captures between individuals showed similarities with a Poisson distribution (Table 2), which Craig's model pre-supposes. However, the field data contained a higher frequency than expected of males that were captured once or $>5$ times. This is the pattern which should be expected when several subsets differing in catchability are combined, and this deviation from the Poisson distribution is smaller when the capture data is divided into subsets (trees and years).

In 3 years, the field work started after the first adults had emerged (Table 1), probably 5-10 days later, and this may have led to bias in the population estimates. The magnitude of this bias was estimated from the data of the 2 years when the first days were also included, by leaving out the captures performed during the 10 days following the emergence of the first adult. For these 2 years, the population size estimate decreased by $5.2 \%$ and $4.6 \%$, respectively, when the captures of the 10 first days were deleted (estimated for 26 trees overall, males and females combined).

The time between the first and last capture was approximately equal for male and female individuals (Table 3). However, male captures greatly outnumbered female captures (Table 2). The sex ratio was determined by estimating the total number of males and females in 1996-1999, using Craig's model with capture data of males and females separated, but with all trees and years combined. This resulted in a sex ratio near 1:1 (Table 4). Calculating the population size with male and female data combined, gave rise to an underestimate; the 
estimate was $25 \%$ higher with male and female data separated compared to combined in 1996-1999. Therefore, the population size was calculated by using the estimates per tree, per year and correcting them for differing catchability between sexes (by multiplying the estimates by 1.25). The population estimates with male and female data combined (Table 5) yielded an average population size of 9 adults tree ${ }^{-1}$ year $^{-1}$, and thus the corrected value is 11 . The variability in population size between trees was very large (Table 5). The population size estimates did not differ between Craig's and the Jolly-Seber method (Table 4).

\section{Temporal variability}

It was only possible to obtain temporal variability data per tree from the eight trees with the largest populations. They sustain $94 \%$ of the total population, so their influence on the temporal variability overall was of utmost importance compared to the remaining trees.

The temporal variability was very small in the studied trees combined, but greater within each tree. The populations in five trees out of eight had C.V.s significantly larger than expected from sampling errors alone $(P<0.05$, Monte Carlo simulations, Table 5$)$. The mean C.V. for the populations in the eight trees was 0.51 . The C.V. for the eight trees combined was 0.16 , approximately the same as the C.V. for all 26 trees, which was 0.15 .

The variability between subsequent years and between generations was compared for the populations in each tree. The variability between two subsequent years (mean C.V., 0.37, $n=4$ ) did not differ from the variability between generations (between 1995 and 1998, and between 1996 and 1999, mean C.V., 0.53, $n=2)(P=0.389$, tested with ANOVA, C.V. for each tree was the dependent variable, tree and generations/subsequent years were independent factors; there was no interaction).

In each year, the mean temperature was lower than the long-term average during spring and early summer. The mean temperature during the time of activity was higher than the average in all years but 1998 [July and August: 1995, 17.0 ${ }^{\circ}$; 1996, 15.8 C; 1997, $18.7^{\circ} \mathrm{C}$; $1998,14.3^{\circ} \mathrm{C} ; 1999,16.8 \mathrm{C}$; mean $(1961-1990), 15.8^{\circ} \mathrm{C}$. Data from the meteorological station of Malmslätt, 20 km from Bjärka-Säby].

\section{Synchrony of variability}

The mean variability per tree was significantly greater than the simulated variability from sampling errors alone (C.V., field data, 0.51; median from simulations, $0.30, P=0.008$ ). No difference was found in a similar simulation of the variability in eight trees combined (C.V., field data, 0.16; median from simulations, $0.14, P=0.334$ ). 
For the eight trees, the synchrony of fluctuations between populations per tree was analysed by calculating the Pearson correlation coefficient between a derived value $(V)$ of the population size per year in one tree and a derived value of the sum from the remaining seven trees. $V$ for the year $t$ was calculated as follows: $V(t)=\ln [\text { population size }+1]_{t+1}-\ln$ [population size+1 $]_{t}$.

This value was used in order to remove the possible autocorrelation which may occur in time series. The correlation had a positive tendency for four populations and negative for the other four, but no correlation was statistically significant (Table 5).

Constancy in spatial variability

With a few exceptions, the same six trees sustained the largest populations every year (Table 5). In six trees, $O$. eremita was never captured and in 14 trees a few (on average 0-5 $O$. eremita tree $^{-1}$ year $^{-1}$ ) adults were present each year.

The variance in the population sizes (ln transformed) between years (for eight trees) was larger than the variance between trees (for 5 years) $(P=0.031, t$-test $)$.

\section{Discussion}

Population size

If it is assumed that the abundance is equal in trees not studied and in trees studied, then the number of O. eremita in 112 hollow oaks with wood mould at Bjärka- Säby is approximately 1,300 adults year-1. Thus, in the three cohorts, the total number of individuals which will emerge as adults is estimated to be 3,900. As trapping was only possible in trees with certain characteristics, there might be a difference in the population size between trees with and without traps. However, there is no indication whether trees without traps would have larger or smaller population sizes; those trees which contained the largest number of beetles did not differ from other trees with traps with respect to those characteristics that determined whether trapping was possible or not (height of the entrance hollow, how far the wood mould surface was from the entrance, and size of the entrance; (unpublished data)). As the population size differed widely between trees, there is much uncertainty regarding the population estimate when only the number of hollow trees is known. Moreover, there are many trees with small hollows (for example woodpecker holes) in the study area which were excluded from the estimation of hollow tree density, as it is not known whether they contain enough wood mould for $O$. eremita. If some of these trees are inhabited by $O$. eremita, the population size is larger. 
The sex ratio seems to be $1: 1$, but there was a strong male bias in the captures. The same pattern has also been recorded from pitfall trapping of some other taxa Thomas et al. 1998).

\section{Temporal variability}

The constancy in size of the total $O$. eremita population differs considerably from that of many other insect populations, which display large fluctuations of 10-1,000 times between generations [e.g. gyrinids (Nürnberger 1996), aphids (Dixon 1990), spruce budworm (Royama 1984) and lygaeids (Solbreck 1991). There are also insects which show moderate variability (hoverflies: Owen and Gilbert 1989, dragonflies: Crowley and Johnson 1992, some butterflies: Pollard and Yates 1993, carabid beetles: Luff 1982), which vary with the same magnitude as for $O$. eremita per tree, but more than for $O$. eremita for all trees combined. Comparing the results of variability studies is however somewhat dubious, as the C.V. not only reflects the population dynamics that are typical for the studied species, but is also influenced by population size and the temporal and spatial scale of the study. This is because temporal variability is always more or less overestimated due to "contamination" with spatial variation (McArdle 1992; Stewart- Oaten et al. 1995) and sampling error (Link and Nichols 1994; Mönkkönen and Aspi 1997), and is correlated with the size of the population (McArdle et al. 1990).

Pimm and Redfearn (1988) have pointed out that the variability in population size increases when more generations are included in the calculation. The normal life cycle of $O$. eremita is probably 3 years, and this means there were three different cohorts in 1995-1997, and the offspring from 1995 and 1996 emerged in 1998 and 1999, respectively. Theoretically, there may be factors which increase as well as factors which decrease variability between cohorts compared to between parents and offspring. For example, moths with a life cycle of 2 years consistently show very large fluctuations between cohorts in subsequent years but smaller fluctuations between parents and offspring, probably due to fluctuations in parasitoid abundance (Mikkola 1976). However, the population sizes of cohorts that are produced close in time could also be positively correlated as they are partly affected by the same environmental conditions (Gaston and McArdle 1994). In this study on O. eremita, none of these factors were strong enough to give rise to any difference in variability between cohorts compared to between parents and offspring.

Populations living in more stable habitats are less variable (Oghushi and Sawada 1981; Wolda et al. 1992), and this could explain the narrow fluctuations of the $O$. eremita populations. The nutrient supply might be constant for O. eremita as wood continuously 
decomposes inside a trunk hollow. The microclimate inside a trunk is stable and not very sensitive to weather fluctuations. Many insect populations are affected by weather (e.g. Kingsolver 1989; Solbreck 1991; Pollard and Yates 1993; Whittaker and Tribe 1998) or parasitoid abundance (Mikkola 1976) over large areas. In contrast, the populations of $O$. eremita fluctuated yearly in each tree rather independently of each other, even though the weather conditions varied between years similarly for all the trees studied.

\section{Asynchrony in variability}

The strongest evidence for the fairly independent fluctuation of populations in each tree is that the Monte Carlo simulation revealed that there were no statistically significant fluctuations overall, although there were fluctuations at the tree level. In a metapopulation consisting of local populations fluctuating independently of each other, the metapopulation variability decreases with spatial scale because local fluctuations tend to cancel each other out when they are added together (Murdoch et al. 1985). Another effect, giving the same result, is that the sampling error becomes larger when the sample size is smaller (Link and Nichols 1994; Mönkkönen and Aspi 1997), and this might be a reason for smaller fluctuations overall in many cases. The Monte Carlo simulations showed that also in this study we should expect a larger C.V. at the tree level than for the population combined due to sampling errors; however, not as large a difference as there was in the field data.

Only half of the populations showed a tendency to fluctuate positively with the total population size in the remaining seven trees. This is also an indication of asynchrony, but it is difficult to determine the influence of sampling errors in this kind of analysis.

\section{Constancy in spatial variability}

The variability was much larger between trees than between years. At the time scale studied, the spatial variability pattern mostly persisted between years, mainly due to moderate variability of population size per tree. This suggests that the population dynamics are determined by factors which are stable in time but variable between trees, e.g. microclimate or nutrient supply.

\section{Species preservation}

Fragmentation and decline of habitats with old trees have caused $O$. eremita and other beetles dependent on hollow trees to become confined to small sites without connectivity (McLean and Speight 1993; Luce 1996; Ranius 2000). According to the minimum viable 
metapopulation size concept, the persistence of a metapopulation increases with the number of patches sustaining local populations (Hanski et al. 1996). As a rule of thumb at least ten occupied patches are needed for the long-term survival of a metapopulation (Hanski 1997). This study indicates that only a minor fraction of the trees with wood mould sustain large populations of $O$. eremita, and there- fore an assemblage of some tens of hollow trees might be needed for metapopulation persistence.

The persistence of a metapopulation is generally facilitated by decreasing distances between habitat patches, as this promotes colonization and rescue effect (Hanski 1994). This may not always be the case, however, as synchrony between local populations tends to decrease the persistence of the metapopulation. Therefore, if asynchrony increases with distance, it may not be optimal to concentrate the habitat patches, but to maintain a distance between patches which exceeds the range within which the population fluctuations are correlated (Kindvall 1996). A decreased distance between local populations increases synchrony for some insects, at least on a large-scale level (Thomas 1991; Hanski and Woiwod 1993; Sutcliffe et al. 1996), but not for others (Kindvall 1996). The results from this study suggest that there is no strong synchrony of $O$. eremita populations even within a stand of trees. Therefore, it seems to be the best strategy to preserve assemblages of hollow trees as large and concentrated as possible, to promote the longterm survival of O. eremita.

Inbreeding depression is usually of minor importance when the effective population size exceeds 50 individuals, but this differs considerably between populations, dependent among other things on the history of the population (Lande 1999). To retain a potential for evolutionary adaptations to environmental changes, the population size must be much larger; theoretical studies have predicted that an effective population size of 500-5,000 is required (Frankham 1995a; Lande 1995; Lynch 1996). As the O. eremita population in the present study area (Bjärka-Säby) was estimated to 3,900 individuals, and the effective population size normally is much lower than the censused population size (Frankham 1995b), it might have a somewhat reduced evolutionary potential. Most populations of $O$. eremita inhabit localities which are much smaller, and there the genetic effects may have a considerably larger influence on the population viability.

It has been argued that local extinctions and colonizations in metapopulations of rare and declining species are usually consequences of successional changes of the habitat (Thomas 1994). Also the habitat of $O$. eremita, hollow trees, changes successively and has a limited duration. Therefore, to maintain an O. eremita metapopulation in the long run, it is not enough to preserve existing hollow trees, but new hollow trees must be continuously 
established within the dispersal range of the species. In areas with hollow trees, on principle three measures may be taken for the long-term survival of $O$. eremita and other threatened saproxylic beetles (Ranius and Jansson 2000): (1) maintain the quality of existing trees, e.g. by continued/resumed grazing of pasture woodlands to avoid forest regrowth, (2) prolong the life-time of existing trees by carefully removing trees in the surrounding which compete for nutrients, water and sunshine, (3) allow new trees to be established and speed up their ageing. Even within the existence of a tree hollow there is a successive change of the habitat characteristics which probably influence its suitability for $O$. eremita. However, it is not possible to understand the dynamics of the habitat quality in more detail yet, as studies over very long periods are required.

\section{Acknowledgements}

Sven G. Nilsson and Per Douwes have given valuable comments on the manuscript and the performance of the field work. Håkan Edlund helped me with the construction of simulation programs. Jonas Hedin has helped with the collection of some field data. This study was financially supported by Stiftelsen Eklandskapsfonden i Linköpings kommun and SUFOR.

\section{References}

Anonymous (1992) Directive 92/43 of the Council of the European Community on the conservation of habitats and wild fauna and flora. European Community, Brussels

Antonsson K, Wadstein M (1991) The oak district. An inventory of meadows and deciduous forests in the oak district south of Linköping (in Swedish). Länsstyrelsen i

Östergötlands län, Linköping

Craig CC (1953) On the utilization of marked specimens in estimating populations of flying insects. Biometrika 40:170-176

Crowley PH, Johnson DM (1992) Variability and stability of a dragonfly assemblage. Oecologia 90:260-269

Dixon AFG (1990) Population dynamics and abundance of deciduous tree-dwelling aphids. In: Watt AD, Leather SR, Hunter MD, Kidd NAC (eds) Population dynamics of forest insects. Intercept, Andover, Hampshire, UK, pp 11-23

Doak DF, Mills LS (1994) A useful role for theory in conservation. Ecology 75:615-626 Foley P (1997) Extinction models for local populations. In: Hanski I, Gilpin ME (eds) Metapopulation biology. Ecology, genetics, and evolution. Academic Press, San Diego, 
Calif., pp 215-246 Frankham R (1995a) Conservation genetics. Annu Rev Genet 29:305-327

Frankham R (1995b) Effective population size/adult population size ratios in wildlife: a review. Genet Res 66:95-107

Gaston KJ, McArdle BH (1994) The temporal variability of animal abundances: measures, methods and patterns. Philos Trans R Soc London Ser B 345:335-358

Goodman D (1987) The demography of chance extinction. In: Soulé ME (ed) Viable populations for conservation. Cambridge University Press, Cambridge, pp 11-34

Hansen V (1925) The fauna of Denmark. Beetles VI. Scarabaeids (in Danish). GEC Gads, Copenhagen

Hanski I (1994) A practical model of metapopulation dynamics. J Anim Ecol 63:151-162

Hanski I (1997) Metapopulation dynamics: from concepts and observations to predictive models. In: Hanski I, Gilpin ME (eds) Metapopulation biology. Ecology, genetics, and evolution. Academic Press, San Diego, Calif., pp 69-91

Hanski I, Simberloff D (1997) The metapopulation approach, its history, conceptual domain, and application to conservation. In: Hanski I, Gilpin ME (eds) Metapopulation biology. Ecology, genetics, and evolution. Academic Press, San Diego, Calif., pp 5-26

Hanski I, Woiwod IP (1993) Spatial synchrony in the dynamics of moth and aphid populations. J Anim Ecol 62:656-668

Hanski I, Pakkala T, Kuussaari M, Lei G (1995) Metapopulation persistence of an endangered butterfly in a fragmented landscape. Oikos 72:21-28

Hanski I, Moilanen A, Gyllenberg M (1996) Minimum viable metapopulation size. Am Nat $147: 527-541$

Harrison S, Quinn JF (1989) Correlated environments and the persistence of metapopulations. Oikos 56:293-298

Jolly GM (1965) Explicit estimates from capture-recapture data with both death and immigration-stochastic model. Biometrika 52:225-247

Kelner-Pillault S (1974) Étude écologique du peuplement entomologique des terraux d'arbres creux (chataigners et saules). Bull Ecol 5:123-156

Kindvall O (1996) Habitat heterogeneity and survival in a bush cricket metapopulation. Ecology 77:207-214

Kingsolver JG (1989) Weather and the population dynamics of insects: integrating physiological and population ecology. Physiol Zool 62:314-334

Lande R (1995) Mutation and conservation. Conserv Biol 9: 782-791 
Lande R (1999) Extinction risks from anthropogenic, ecological and genetic factors. In:

Landweber LF, Dobson AP (eds) Genetics and the extinction of species. Princeton University Press, Princeton, N.J., pp 1-22

Link WA, Nichols JD (1994) On the importance of sampling variance to investigations of temporal variation in animal population size. Oikos 69:539-544

Luce JM (1996) Osmoderma eremita (Scopoli, 1763). In: Helsdingen PJ van, Willemse L, Speight MCD (eds) Background information on invertebrates of the Habitats Directive and the Bern Convention. Part 1. Crustacea, Coleoptera and Lepidoptera. Council of Europe, Strasbourg, pp 64-69

Luff ML (1982) Population dynamics of Carabidae. Ann Appl Biol 101:164-170 Lynch M (1996) A quantitative-genetic perspective on conservation issues. In: Avise JC, Hamrick JL (eds) Conservation genetics: case histories from nature. Chapman and Hall, New York, pp 471-501

Martin O (1993) Protected insects in Denmark. Part 2. Beetles connected with forests (in Danish). Entomol Medd 61:63-76

McArdle BH (1992) Comparing population variabilities. Oikos 64:610-612

McArdle BH, Gaston KJ, Lawton JH (1990) Variation in the size of animal populations: patterns, problems and artefacts. J Anim Ecol 59:439-454

McLean IFG, Speight MCD (1993) Saproxylic invertebrates - the European context. In: Kirby KJ, Drake CM (eds) Dead wood matters: the ecology and conservation of saproxylic invertebrates in Britain. English Nature Science no. 7. English Nature, Peterborough, pp 21-32

Mikkola K (1976) Alternate-year flight of northern Xestia species (Lep., Noctuidae) and its adaptive significance. Ann Entomol Fenn 42:191-199

Mönkkönen M, Aspi J (1997) Sampling error in measuring temporal density variability in animal populations and communities. Ann Zool Fenn 34:47-57

Murdoch WW, Chesson J, Chesson PL (1985) Biological control in theory and practice. Am Nat 125:344-366

Nilsson T (1997) Spatial population dynamics of the black tinder fungus beetle Bolitophagus reticulatus (Coleoptera: Tenebrionidae). Dissertation. Faculty of Science and Technology, Uppsala

Nürnberger B (1996) Local dynamics and dispersal in a structured population of the whirligig beetle Dineutus assimilis. Oecologia 106:325-336 
Oghushi T, Sawada H (1981) The dynamics of natural populations of a phytophagous lady beetle, Henosepilachna pustulosa (Kono) under different habitat conditions. I. Comparison of adult population parameters among local populations in relation to habitat stability. Res Popul Ecol 23:94-115

Owen J, Gilbert FS (1989) On the abundance of hoverflies (Syrphidae). Oikos 55:183-193

Park O, Auerbach S (1954) Further study of the tree-hole complex with emphasis on quantitative aspects of the fauna. Ecology 32:208-222

Pimm SL (1991) The balance of nature? Ecological issues in the conservation of species and communities. University of Chicago Press, Chicago, Ill.

Pimm SL, Redfearn A (1988) The variability of population densities. Nature 334:613-614

Polis GA, Barnes JD, Seely MK, Henschel MK, Enders MM (1998) Predation as a major cost of reproduction in Namib Desert tenebrionid beetles. Ecology 79:2560-2566

Pollard E, Yates TJ (1993) Monitoring butterflies for ecology and conservation. Chapman and Hall, London

Ranius T (2000) Minimum viable metapopulation size of a beetle, Osmoderma eremita, living in tree hollows. Anim Conserv 3:37-43

Ranius T, Hedin J (in press) the dispersal rate of a beetle, Osmoderma eremita, living in tree hollows. Oecologia

Ranius T, Jansson N (2000) The influence of forest regrowth, original canopy cover and tree size on saproxylic beetles associated with old oaks. Biol Conserv 95:85-94

Ranius T, Nilsson SG (1997) Habitat of Osmoderma eremita Scop. (Coleoptera: Scarabaeidae), a beetle living in hollow trees. J Insect Conserv 1:193-204

Royama T (1984) Population dynamics of the spruce budworm Choristoneura fumiferana. Ecol Monogr 54:429-462

Saccheri I, Kuusaari M, Kankare M, Vikman P, Fortelius W, Hanski I (1998) Inbreeding and extinction in a butterfly metapopulation. Nature 392:491-494

Solbreck C (1991) Unususal weather and insect population dynamics: Lygaeus equestris during an extinction and recovery period. Oikos 60:343-350

Southwood TRE (1978) Ecological methods with particular reference to the study of insect populations, 2nd edn. Chapman and Hall, London Speight MCD (1989) Saproxylic invertebrates and their conservation. Council of Europe, Strasbourg

Stewart-Oaten A, Murdoch WW, Walde SJ (1995) Estimation of temporal variability in populations. Am Nat 146:519-535 
Sutcliffe OE, Thomas CD, Moss D (1996) Spatial synchrony and asynchrony in butterfly population dynamics. J Anim Ecol 65:85-95

Tauzin P (1994) Le genre Osmoderma Le Peletier et Audinet- Serville 1828 (Coleopt., Cetoniidae, Trichiinae, Osmodermatini). Systématique, biologie et distribution (deuxième partie). Entomologiste 50:217-242

Thomas CD (1991) Spatial and temporal variability in a butterfly population. Oecologia $87: 577-580$

Thomas CD (1994) Extinction, colonization, and metapopulations: environmental tracking by rare species. Conserv Biol 8: 373-378

Thomas CD, Hanski I (1997) Butterfly metapopulations. In: Hanski I, Gilpin ME (eds) Metapopulation biology. Ecology, genetics, and evolution. Academic Press, San Diego, Calif., pp 359-386 Thomas CFG, Parkinson L, Marshall EJP (1998) Isolating the components of activity-density for the carabid beetle Pterostichus melanarius in farmland. Oecologia 116:103-112

Topping CJ, Sunderland KJ (1992) Limitations to the use of pitfall traps in ecological studies exemplified by a study of spiders in a field of winter wheat. J Appl Ecol 29:485-491

Whittaker JB, Tribe NP (1998) Predicting numbers of an insect (Neophilaenus lineatus: Homoptera) in a changing climate. J Anim Ecol 67:987-991

Wolda H, Spitzer K, Leps J (1992) Stability of environment and of insect populations. Res Popul Ecol 34:213-225

Wright SJ, Hubbell SP (1983) Stochastic extinction and reserve size: a focal species approach. Oikos 41:466-476 


\section{Table 1}

Capture data of O. eremita per year. Starting date The date when the first adult was captured in the field, Ending date date when the last individual was captured, Captures total number of captures in the 26 trees of the study, Captured individuals total number of individuals captured in the 26 trees of the study

$\begin{array}{lllll}\text { Year } & \begin{array}{l}\text { Starting } \\ \text { date }\end{array} & \begin{array}{l}\text { Ending } \\ \text { date }\end{array} & \text { Captures } & \begin{array}{l}\text { Captured } \\ \text { individuals }\end{array} \\ 1995 & \text { 21 July }^{\text {a }} & \text { 25 August } & 283 & 165 \\ 1996 & \text { 27 July }^{2} & \text { 7 September } & 223 & 109 \\ 1997 & \text { 14 July }^{\text {a }} & \text { 25 August } & 314 & 142 \\ 1998 & \text { 21 July } & \text { 2 September } & 464 & 162 \\ 1999 & \text { 8 July }^{\text {a }} & \text { 15 August } & 257 & 145 \\ \text { Sum } & & & 1,541 & 723\end{array}$

${ }^{\text {a }}$ Adults present on the first day of field work 


\section{Table 2}

The captured $O$. eremita individuals divided into groups according to how many times they were captured. Frequencies of males and females from the field data of 1996-1999 (not all individuals were sexed in 1995), and the frequencies expected from the Poisson distribution

\begin{tabular}{lllll}
$\begin{array}{l}\text { No. of } \\
\text { captures }\end{array}$ & Males & \multicolumn{3}{l}{ Females } \\
& $\begin{array}{l}\text { Field } \\
\text { data }\end{array}$ & $\begin{array}{l}\text { Poisson } \\
\text { distribution }\end{array}$ & $\begin{array}{l}\text { Field } \\
\text { data }\end{array}$ & $\begin{array}{l}\text { Poisson } \\
\text { distribution }\end{array}$ \\
0 & - & 39 & - & 224 \\
1 & 160 & 94 & 132 & 127 \\
2 & 81 & 112 & 29 & 36 \\
3 & 48 & 89 & 6 & 7 \\
4 & 27 & 53 & 4 & 1 \\
5 & 28 & 25 & 0 & 0.1 \\
6 & 20 & 10 & 0 & $<0.1$ \\
7 & 7 & 3 & 0 & $<0.1$ \\
8 & 8 & 1 & 0 & $<0.1$ \\
9 & 4 & 0.3 & 0 & $<0.1$ \\
10 & 1 & $<0.1$ & 0 & $<0.1$ \\
$>10$ & 3 & $<0.1$ & 0 & $<0.1$ \\
Sum & 387 & 426 & 171 & 395
\end{tabular}




\section{Table 3}

The recaptured $O$. eremita individuals in 1996-1999, divided into groups according to the time elapsed between the first and last capture

$\begin{array}{lll}\text { Days } & \text { Males } & \text { Females } \\ 1-9 & 138 & 27 \\ 10-19 & 67 & 8 \\ 20-29 & 20 & 3 \\ 30-39 & 2 & 1\end{array}$




\section{Table 4}

Estimates of the population size for 4 years (1996-1999), total with confidence limits

$\begin{array}{llll}\begin{array}{l}\text { Population } \\ \text { subset }\end{array} & \text { Method } & \begin{array}{l}\text { Population } \\ \text { size }\end{array} & \begin{array}{l}\text { Confidence } \\ \text { limits }\end{array} \\ \begin{array}{lll}\text { Males } \\ \text { Femalesa }\end{array} & \text { Craig } & 426 & 410-441 \\ \text { Combined sexes }^{\text {a }}{ }^{\text {Males, }} & \text { Craig } & 395 & 319-493 \\ \quad \text { Craig } & 658 & 633-688 \\ \text { with correction }^{\text {b }} & \text { Craig } & 569 & - \\ \text { Males }^{c} & & & \\ & \text { Jolly-Seber } & 584 & -\end{array}$

${ }^{\mathrm{a}}$ From a pooled sample including all trees

${ }^{\mathrm{b}}$ Data corrected for different catchability between sexes. The population sizes for every tree (see Table 2) was summed, divided by 2 (as the sex ratio was 1:1) and multiplied by 1.25 (to correct for the bias which arise when sexes are combined)

${ }^{\mathrm{c}}$ Males estimated by the Jolly-Seber method from a pooled sample including all trees 


\section{Table 5}

Population size (Pop.; i.e. the number of adults per tree and year estimated by Craig's model, without correction for differences in catchability between males and females) with $95 \%$ confidence limits. Coefficient of variation $(C . V)=.\mathrm{SD} /$ mean population size for 5 years and significance level of the C.V. in relation to a Monte Carlo simulation with temporal variability caused by sampling errors alone

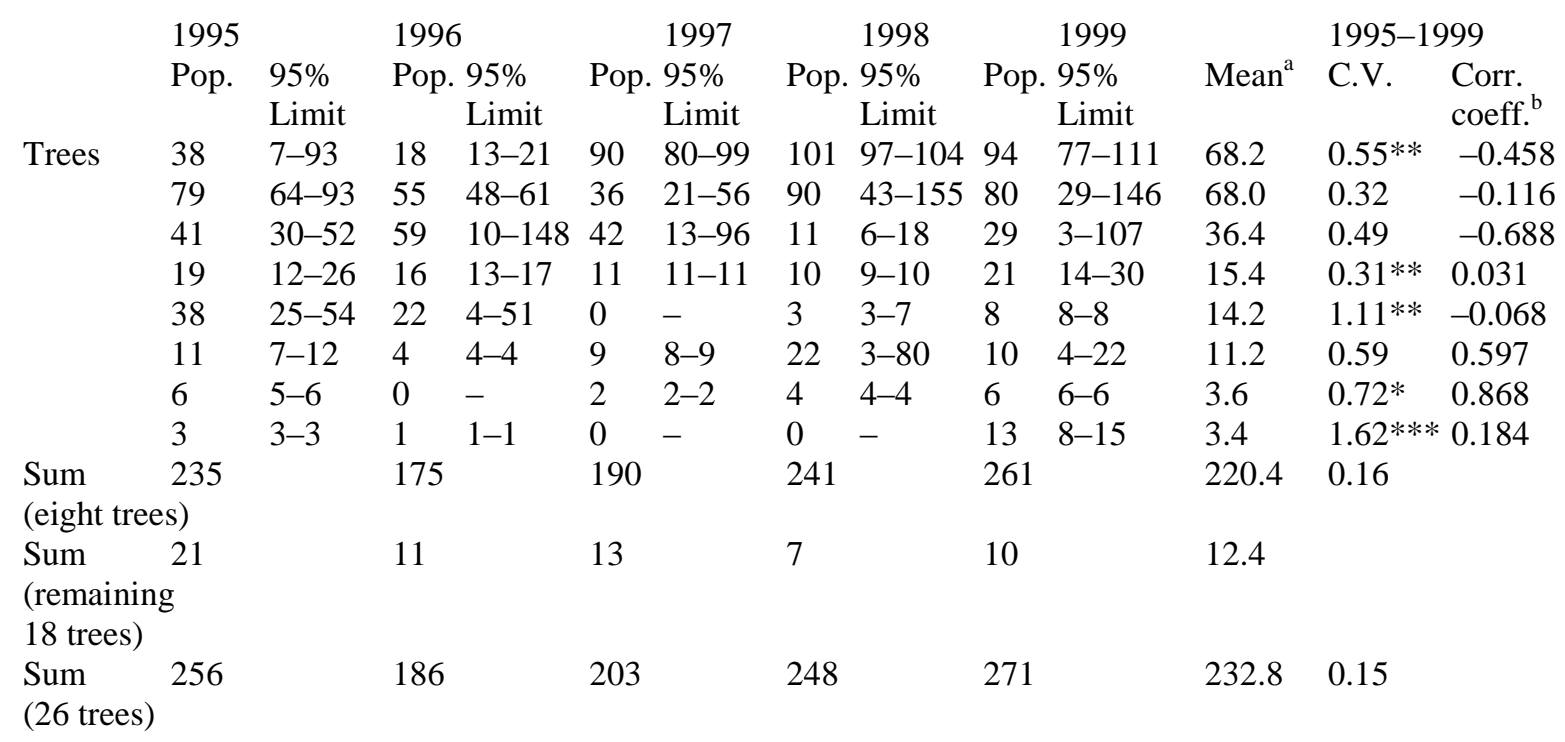

$* P<0.05 ; * * P<0.01 ; * * * P<0.001 ;{ }^{a}$ Arithmetic mean of the population size 1995-1999;

${ }^{\mathrm{b}}$ Pearson correlation coefficient (corr. coeff.) between population size per year in the tree and the other seven trees (ln transformed and with autocorrelation considered; see Results) 